\title{
THE CREATION OF SOCIAL CAPITAL IN RURAL AREAS IN THE LUBELSKIE REGION
}

Aneta JAROSZ-ANGOWSKA, Department of Economics and Agribusiness, University of Life Sciences in Lublin, Akademicka 13 str., 20-950 Lublin, Poland. aneta.angowska@up.lublin.pl (corresponding author)

Marek ANGOWSKI, Department of Management and Marketing, University of Life Sciences in Lublin, Akademicka 13 str., 20-950 Lublin, Poland. marek.angowski@up.lublin.pl

Tomasz KIJEK, Department of Economics and Agribusiness, University of Life Sciences in Lublin, Akademicka 13 str., 20-950 Lublin, Poland. tomasz.kijek@up.lublin.pl

Social capital is one of the pillars of sustainable development of rural areas because the modern village needs educated and enterprising people and communities that can adapt quickly to changes and cooperate. The main aim of this article is to evaluate the different components of social capital and attempt to answer the question whether social capital in the rural areas of the Lubelskie Voivodeship differs from the social capital in the urban areas of the region. First, the study quotes the main definitions of social capital by J. Coleman, R. Putnam and F. Fukuyama, and next, separates its components for analysis. The analysis of such components as trust, friendship, cooperation, engagement in activities for the benefit of local community, participation in organisations, obtaining information and the level of communication, participation in elections and the assessment of democracy made it possible to conclude that, in principle, there are no significant differences between social capital in rural and urban areas of the Lubelskie Region, which can be explained by the fact that rural areas are losing its traditional agricultural character, and the mixing of population - the rural population flows into urban areas and the urban population settles in the countryside. The evaluation was conducted on the basis of questionnaire research commissioned by the Marshal Office in Lublin, and carried out on a sample of 1100 residents of the Lubelskie Voivodeship.

Keywords: cooperation, organizational participation, rural and urban areas, social capital, trust

\section{INTRODUCTION}

The issue of social capital appeared in the literature for the first time in 1916 in a work by L. J. Hanifan, where the author wrote about rural educational centres. In the 1970s, advanced research on this was carried out by G. Loury, who introduced the concept of social capital to social sciences. Nowadays, research on social capital is based on the three - seemingly most significant - theories: concepts put forward by J. Coleman, R. Putnam and F. Fukuyama (Raczkowska, 2009). Coleman defines social capital as the features of social organisation such as trust, standards and relationships between units that increase their efficiency in collective actions, and, at the same time, make them a community, allowing them to achieve certain goals impossible to implement without this capital (Coleman, 1990). Developing Coleman's approach, Robert Putnam states that social capital refers to such features of social organisation as trust, norms and links that can increase the efficiency of society by facilitating coordinated action (Frieske, 2004). In analysing approaches to social capital research it is worth paying attention to the definition formulated by Fukuyama. This researcher defines social capital, like Putnam, as a set of informal values and ethical standards common to members of a specific group which enable their effective cooperation (Fukuyama, 1997). Participation in associational activities is seen as a key indicator of a socially healthy, engaged and equal society. It is the basic argument of Putnam's very prominent work (Putnam, 2000) which has influenced the World Bank, the European Union and many other development programmes. Putnam argues that dense networks of civic engagement produce a capacity for trust, reciprocity and cooperation ('social capital'), which in turn leads to a healthy economy and a healthy democracy. Putnam's measure of civicness or social capital includes associational activity, newspaper readership and some aspects of voting behaviour. He argues that norms and networks of civic engagement undergird good government.

The concept of social capital has been recently one of the most important issues in the debate about Poland's development opportunities, and has appeared in various contexts connected with rural development. An increase in social capital is mentioned in the report "Poland 2030. Development Challenges" as one of the 10 challenges facing Poland in years to come. Tasks related to the strengthening of social capital are included in the Social Capital Development Strategy for 20112020 (SCDS), whose formation is coordinated by the Ministry of Culture. Different definitions and suggestions for ways to measure social capital are being created in scientific discussions on this concept, but the most useful definition seems to be

Copyright (C) 2015 The Authors. Published by Aleksandras Stulginskis University. This is an open-access article distributed under the terms of the Creative Commons Attribution License (CC-BY 4.0), which permits unrestricted use, distribution, and reproduction in any medium, provided the original author and source are credited. 
formulated in SCDS: "arising from trust and norms and patterns of behaviour, the ability of citizens to mobilise and pool resources, which fosters creativity and strengthens the will for cooperation and understanding in achieving common goals."

Social capital is credited with facilitating rural development (Anderson and Bell, 2003). Rural areas have fewer opportunities than urban centres due to a number of negative factors, including a low level of economic development, high employment in agriculture and a limited number of non-agricultural jobs, a low educational level, low awareness of the benefits of education, and difficulties in access to the social, educational and cultural infrastructure. The abovementioned factors result in a decrease in solidarity, social trust, and generate a sense of injustice. They become the cause of social conflicts (Raczkowska, 2009). The main objective of this article is finding whether the capital in rural areas differs from that of urban areas. In the literature, at least four different views regarding this subject can be distinguished.

The first and most traditional point of view states that relationships in the urban space are typically shallow, shortlived and formal because of the size, density, and the heterogeneous social nature of the city (Wirth, 1938; Lannoo et al., 2011; Park, 1915). These characteristics result in less individual social capital in urban areas. Nowadays, these historical claims have been rearticulated, though in slightly different forms, by scholars sceptical of urbanisation (Putnam, 2000). A second perspective does not deny the distinct nature of the city, but states that an urban space results in different kinds of individual social capital instead of lowering its amount. Some have stated that an urban environment might stimulate the creation of social capital, because the increased liberty in network formation might result in more supportive networks (Lannoo et al., 2011). A third view only accepts the thesis regarding the distinct social composition of the city and argues that urban-rural differences in individual social capital are only due to compositional effects, i.e. to the fact that people with different characteristics, and thus with different levels of social capital, are inclined to live in the city, the suburbs or in the country (Kasarda and Janowitz, 1974; Goudy, 1990; Lannoo et al., 2011). The fourth and final point of view asserts that the countryside is in fact urbanised because of cheap and efficient transportation and communication technologies, which gradually leads to the total elimination of urban-rural differences in social capital (Friedland, 1982; Lannoo et al., 2011).

To achieve the main objective of the article social capital will be analysed in respect of the following components: trust and friendship, cooperation: preparedness and the range of activities for the benefit of the local community, organisational participation and its diversity, information and communication - for example the use of the press and other sources of information, the impact on the surrounding world and in particular on its key institutions.

\section{RESEARCH METHOD}

The survey of the region's residents was part of the research project entitled "Intellectual Capital of the Lubelskie Region 2010-2013", carried out by the Statistical Office in Lublin for the Marshal Office of the Lubelskie Voivodeship under Priority VIII Regional human resources, Measure 8.2 Transfer of knowledge, Measure 8.2.2 Regional Innovation Strategies of the Human Capital Programme for 2007-2013. The main objective of the project was to measure the intellectual capital of the region, and thereby provide a basis for making key decisions on the future of the region and its residents. It was to allow the verification of two of the four elementary components of intellectual capital - human capital and social capital. The survey of the region's residents was carried out using a representative method on a sample of 1100 respondents, maintaining proportionality characteristics such as gender, age and place of residence (with the division by the rural areas, small and mediumsized towns and cities with more than 100,000 residents). The representative random sample was drawn from the register of PESEL numbers. The sample selection was in line with the nature of the quota by the above-mentioned categories. The survey was conducted in 2012 by field interviewers from the Statistical Office in Lublin. Due to the breadth of the questionnaire and the sample size it was decided that the study of the residents would be conducted using the CAPI method (Computer-Assisted Personal Interviewing). Among the respondents, 53.1\% of people lived in rural areas, $20.8 \%$ in urban areas up to 45,000 residents and $26.1 \%$ in cities with more than 45,000 residents. The authors of the publication applied the categories of aggregated urban and rural areas to the analysis. A more detailed characteristics of the respondents is presented in Table 1.

Table 1. Characteristics of the respondents

\begin{tabular}{|l|l|c|c|c|}
\hline Characteristics & Details & total & rural areas & city \\
\hline \multirow{3}{*}{ Aender } & female & $52.2 \%$ & $51.2 \%$ & $53.3 \%$ \\
\cline { 2 - 5 } & male & $47.8 \%$ & $48.8 \%$ & $46.7 \%$ \\
\hline \multirow{5}{*}{ Education level } & $18-29$ age & $23.8 \%$ & $24.3 \%$ & $23.3 \%$ \\
\cline { 2 - 5 } & $20-49$ age & $32.9 \%$ & $32.7 \%$ & $33.1 \%$ \\
\cline { 2 - 5 } & over 50 age & $43.3 \%$ & $43.0 \%$ & $43.6 \%$ \\
\hline \multirow{5}{*}{ Average monthly income } & primary school, lower secondary and incomplete primary & $10.9 \%$ & $14.8 \%$ & $6.8 \%$ \\
\cline { 2 - 5 } & basic vocational & $21.9 \%$ & $28.8 \%$ & $13.9 \%$ \\
\cline { 2 - 5 } & post secondary and secondary & $41.7 \%$ & $40.2 \%$ & $43.6 \%$ \\
\cline { 2 - 5 } & tertiary & $25.5 \%$ & $16.2 \%$ & $35.7 \%$ \\
\hline & no income & $10.5 \%$ & $13.5 \%$ & $6.9 \%$ \\
\cline { 2 - 5 } & to 1000 PLN & $26.2 \%$ & $33.1 \%$ & $18.1 \%$ \\
\cline { 2 - 5 } & $1001-1500$ PLN & $23.5 \%$ & $21.3 \%$ & $25.7 \%$ \\
\cline { 2 - 5 } & $1501-2000$ PLN & $22.3 \%$ & $18.4 \%$ & $26.4 \%$ \\
\cline { 2 - 5 } & $2001-3000$ PLN & $10.5 \%$ & $8.2 \%$ & $12.9 \%$ \\
\cline { 2 - 5 } & over 3000 PLN & $7.0 \%$ & $5.5 \%$ & $10.0 \%$ \\
\hline
\end{tabular}

Source: survey results 


\section{RESEARCH RESULTS}

The assessment of trust in people is presented in Table 2. When asked whether most people can be trusted, $14.9 \%$ of rural residents and $14.2 \%$ of urban population answered "yes". Drawing conclusions based on that question, taken out of context, without considering any circumstances, can be a gross oversimplification, diminishing trust issues. A similar view was expressed earlier by Zagała (2008). As regards the evaluation of the social capital survey, an alternative to the statement "most people can be trusted" is the statement "in contacts with people you should be cautious", implying a more responsible and thoughtful attitude.

Table 2. Assessment of trust in people

\begin{tabular}{|c|c|c|c|}
\hline Characteristics & Village & City & test for difference* \\
\hline Most people can be trusted & $14.9 \%$ & $14.2 \%$ & $\mathrm{Z}=0.329 ; \mathrm{p}=0.742$ \\
\hline Hard to say & $6.7 \%$ & $5.0 \%$ & $\mathrm{Z}=1.206 ; \mathrm{p}=0.228$ \\
\hline In contacts with people you should be careful & $62.8 \%$ & $65.5 \%$ & $\mathrm{Z}=-0.933 ; \mathrm{p}=0.35$ \\
\hline The majority can not be trusted & $15.6 \%$ & $15.3 \%$ & $\mathrm{Z}=0.137 ; \mathrm{p}=0.890$ \\
\hline
\end{tabular}

$* \mathrm{H}_{0}: \mathrm{p}_{\mathrm{v}}=\mathrm{p}_{\mathrm{c}}$ vs $\mathrm{H}_{\mathrm{a}}: \mathrm{p}_{\mathrm{v}} \neq \mathrm{p}_{\mathrm{c}}$, where $\mathrm{p}_{\mathrm{v}}$-proportion for village; $\mathrm{p}_{\mathrm{c}}-$ proportion for city

Source: survey results

According to the survey, the statement that in contacts with people you should be careful was claimed to be true by $62.8 \%$ of rural residents and $65.5 \%$ of urban population. The lack of confidence in people was expressed by $15.6 \%$ of rural residents and $15.3 \%$ of urban residents.

In rural areas more men than women answered that the majority cannot be trusted. The degree of trust in people grows with age. But growing older goes along with the feeling that in dealing with people you should also be careful. There is a simple relationship between the level of education and the level of trust - the degree of trust increases along with the increasing level of education. As for the level of income, a high level of trust was reported among village residents who did not declare any sources of income and those earning PLN 1000-1500 a month.

In the circle of trust with the greatest degree of confidence is enjoyed by the closest and distant family members as well as friends and acquaintances. Respondents place less confidence in their neighbours and the clergy. On the other hand, stronger relationships between neighbours can be observed in rural areas and small towns than in other cities. The neighbourhood institution is an integral part of the social space of the village and has different functions in rural life social, mutual assistance or providing a basis for collective action. The smallest degree of trust is placed in the Parliament and the Government. This situation looks a little better when it comes to local and voivodeship authorities. European institutions rank in the middle between the Government and local authorities. Detailed information is presented in Table 3.

Table 3. Circle of trust

\begin{tabular}{|l|c|c|c|}
\hline Characteristics & village & city & test for difference* \\
\hline Closest family & 4,67 & 4,73 & $\mathrm{~T}=-1,002 ; \mathrm{p}=0,316$ \\
\hline Distant relatives & 3,99 & 3,93 & $\mathrm{~T}=0,838 ; \mathrm{p}=0,402$ \\
\hline Friends, acquaintances & 4,11 & 4,16 & $\mathrm{~T}=-0,793 ; \mathrm{p}=0,427$ \\
\hline Neighbors & 3,53 & 3,40 & $\mathrm{~T}=1,851 ; \mathrm{p}=0,064$ \\
\hline The clergy & 3,25 & 3,11 & $\mathrm{~T}=1,810 ; \mathrm{p}=0,070$ \\
\hline Local government & 2,92 & 2,70 & $\mathrm{~T}=2,902 ; \mathrm{p}=0,003$ \\
\hline Regional authorities & 2,75 & 2,60 & $\mathrm{~T}=2,064 ; \mathrm{p}=0,039$ \\
\hline The courts & 2,90 & 2,78 & $\mathrm{~T}=1,635 ; \mathrm{p}=0,102$ \\
\hline Police & 3,14 & 3,12 & $\mathrm{~T}=0,255 ; \mathrm{p}=0,798$ \\
\hline Government & 2,40 & 2,28 & $\mathrm{~T}=1,676 ; \mathrm{p}=0,093$ \\
\hline Parliament & 2,37 & 2,23 & $\mathrm{~T}=1,928 ; \mathrm{p}=0,054$ \\
\hline President & 2,74 & 2,63 & $\mathrm{~T}=1,515 ; \mathrm{p}=0,130$ \\
\hline The European Institutions & 2,66 & 2,64 & $\mathrm{~T}=0,269 ; \mathrm{p}=0,787$ \\
\hline
\end{tabular}

${ }^{*} \mathrm{H}_{0}: \mathrm{m}_{\mathrm{v}}=\mathrm{m}_{\mathrm{c}} \mathrm{vs}_{\mathrm{a}}: \mathrm{m}_{\mathrm{v}} \neq \mathrm{m}_{\mathrm{c}}$, where $\mathrm{m}_{\mathrm{v}}-$ mean for village; $\mathrm{m}_{\mathrm{c}}-$ mean for city

Scale: 1 - no, 2 - probably not, 3 - difficult to say, 4 - rather yes, 5 - yes

Source: survey results

Another indicator taken into account when assessing social capital was the number of people regarded as friends. Having up to 5 friends was declared by $23.6 \%$ of rural residents and $24 \%$ of the residents of the cities. $39.4 \%$ of rural residents and $38.3 \%$ of the population of the city had 6 to 10 friends. In turn, having 11 to 20 friends was declared by $23.6 \%$ of the rural population and $25.4 \%$ of residents of the cities. $13.4 \%$ of the rural population and $12.3 \%$ of the population of the city had more than 20 friends. $58.1 \%$ of the urban population had friends and acquaintances abroad, while this was true only for $49.7 \%$ of the rural population.

Cooperation is an important measure of social capital: preparedness and the range of activities for the benefit of the local community, identifying potential activities available for social mobilisation. $21.9 \%$ of rural residents and $26.4 \%$ of the population of the city declared involvement in activities for the benefit of the local community. $10.8 \%$ of rural residents and $11 \%$ of the urban population performed a specific function in organisations. In rural areas, there were 
more women than men involved in the local community, but if we consider their functions in these organisations, men were more involved. Commitment to local communities was the greatest in the age group of 30-49 years, the so-called middle-aged people. Also the largest number of specific functions in organisations is held by members of this group. In rural areas, involvement in activities for the benefit of the local community increased with the level of education and with the level of income.

According to studies on the issue, generally in rural areas less activity in various organisations is observed, with the exception of Village Housewives' Associations. Detailed characteristics of activity in organisations by rural and urban areas are presented in Table 4.

Table 4. Activity in organizations in rural and urban areas

\begin{tabular}{|c|c|c|c|}
\hline Activity in organizations & village & city & test for difference* \\
\hline The parental committee, the council of parents, school foundation & $9.1 \%$ & $17.2 \%$ & $\mathrm{Z}=-3.939 ; \mathrm{p}=0.000$ \\
\hline Sports or tourist organizations & $5.3 \%$ & $13.8 \%$ & $\mathrm{Z}=-4.733 ; \mathrm{p}=0.000$ \\
\hline Parish community, church or religious organizations & $10.3 \%$ & $17.4 \%$ & $\mathrm{Z}=-3.382 ; \mathrm{p}=0.000$ \\
\hline The compounds of gardeners, fishermen or hunters' organizations & $1.7 \%$ & $3.3 \%$ & $\mathrm{Z}=-1.681 ; \mathrm{p}=0.092$ \\
\hline Volunteer Fire Department & $5.0 \%$ & $5.6 \%$ & $\mathrm{Z}=-0.443 ; \mathrm{p}=0.658$ \\
\hline Artistic Association (choir, dance team, orchestra) & $2.1 \%$ & $3.3 \%$ & $\mathrm{Z}=-1.218 ; \mathrm{p}=0.223$ \\
\hline Charity organizations acting on behalf of children or people in need & $3.3 \%$ & $10.5 \%$ & $\mathrm{Z}=-4.637 ; \mathrm{p}=0.000$ \\
\hline Animal Friends Society & $0.3 \%$ & $1.9 \%$ & $\mathrm{Z}=-2.486 ; \mathrm{p}=0.012$ \\
\hline Pensioners organizations, seniors clubs & $1.4 \%$ & $4.3 \%$ & $\mathrm{Z}=-2.844 ; \mathrm{p}=0.004$ \\
\hline Association of lovers of the city, region & $1.9 \%$ & $6.4 \%$ & $\mathrm{Z}=-3.679 ; \mathrm{p}=0.000$ \\
\hline Local authorities of the district, residential areas, eg. the council of inhabitants & $2.7 \%$ & $3.5 \%$ & $Z=-0.761 ; p=0.446$ \\
\hline $\begin{array}{l}\text { Committees applying for settlement of a particular case (eg. car park), protest } \\
\text { group }\end{array}$ & $0.7 \%$ & $4.5 \%$ & $\mathrm{Z}=-3.871 ; \mathrm{p}=0.000$ \\
\hline Women's organizations, for example Village Housewives' Associations & $5.5 \%$ & $4.5 \%$ & $\mathrm{Z}=0.762 ; \mathrm{p}=0.445$ \\
\hline Labor unions & $3.1 \%$ & $4.1 \%$ & $\mathrm{Z}=-0.885 ; \mathrm{p}=0.376$ \\
\hline Commune, county or voivodeship councils & $2.7 \%$ & $2.7 \%$ & $\mathrm{Z}=0.000 ; \mathrm{p}=1.000$ \\
\hline Political parties or associations & $1.2 \%$ & $3.3 \%$ & $\mathrm{Z}=-2.313 ; \mathrm{p}=0.020$ \\
\hline Associations, clubs of collectors, gatherers, hobbyists & $1.9 \%$ & $7.0 \%$ & $\mathrm{Z}=-4.030 ; \mathrm{p}=0.000$ \\
\hline Scientific society & $1.2 \%$ & $5.0 \%$ & $\mathrm{Z}=-3.567 ; \mathrm{p}=0.000$ \\
\hline Another & $2.4 \%$ & $5.6 \%$ & $\mathrm{Z}=-2.673 ; \mathrm{p}=0.007$ \\
\hline No action & $67.6 \%$ & $66.9 \%$ & $\mathrm{Z}=0.247 ; \mathrm{p}=0.804$ \\
\hline
\end{tabular}

$* \mathrm{H}_{0}: \mathrm{p}_{\mathrm{v}}=\mathrm{p}_{\mathrm{c}}$ vs $\mathrm{H}_{\mathrm{a}}: \mathrm{p}_{\mathrm{v}} \neq \mathrm{p}_{\mathrm{c}}$, where $\mathrm{p}_{\mathrm{v}}$-proportion for village; $\mathrm{p}_{\mathrm{c}}-$ proportion for city

Source: survey results

The functioning of organisations is subject to similar factors as the functioning of companies. No wonder that their density is greater in the cities, where they can benefit from agglomeration effects and opportunities of cooperating with a variety of public institutions and private entities.

In an information society communication networks are the basis for obtaining information, joint actions and cooperation. Newspapers have a special role in the system of information and communication. The daily or almost daily reading of newspapers was declared by $22 \%$ of rural residents and $29.8 \%$ of the population of the cities. $27.1 \%$ of rural residents declared that they read newspapers less frequently than once a week, while only $16.3 \%$ of the city population gave such an answer. $10.9 \%$ of urban and $12.5 \%$ of rural population never or almost never read newspapers.

Another indicator of information and communication networks is access to the Internet. It can be concluded from the answers given by the respondents that $43.8 \%$ of rural residents and $27.1 \%$ of the urban population do not use the Internet at all. $14.2 \%$ of the rural population and $32.2 \%$ of urban residents have access to the Internet. $40.6 \%$ of rural residents and $38.8 \%$ of urban residents use the Internet only at home, while $1.4 \%$ of the rural population and $1.9 \%$ of the city population use the Internet exclusively at work, which implies that the majority of respondents have access to the Internet in their place of residence. The Internet is used in many ways, mostly to browse websites; it also allows the use of instant messaging applications and social networking services, as presented in Table 5.

Table 5. Use of the Internet - featured activities

\begin{tabular}{|c|c|c|c|}
\hline Use of the Internet & village & city & test for difference* \\
\hline Browse web pages & $50.9 \%$ & $66.1 \%$ & $\mathrm{Z}=-5.119 ; \mathrm{p}=0.000$ \\
\hline Send, receive electronic mail & $40.4 \%$ & $57.6 \%$ & $\mathrm{Z}=-5.699 ; \mathrm{p}=0.000$ \\
\hline Using instant messaging (GG, Skype, ICQ, etc.) & $27.6 \%$ & $44.0 \%$ & $\mathrm{Z}=-5.649 ; \mathrm{p}=0.000$ \\
\hline Using social networks (Facebook, Goldenline etc.) & $32.9 \%$ & $42.4 \%$ & $\mathrm{Z}=-3.324 ; \mathrm{p}=0.001$ \\
\hline Reading newspapers and magazines online & $22.8 \%$ & $39.1 \%$ & $\mathrm{Z}=-5.815 ; \mathrm{p}=0.000$ \\
\hline Using online banking & $26.9 \%$ & $44.6 \%$ & $Z=-6.098 ; p=0.000$ \\
\hline $\begin{array}{l}\text { Using the services of public administration (eg. to } \\
\text { download official forms, sending filled in forms) }\end{array}$ & $13.4 \%$ & $28.9 \%$ & $Z=-6.237 ; p=0.000$ \\
\hline Online courses, e-learning & $2.7 \%$ & $12.8 \%$ & $\mathrm{Z}=-6.146 ; p=0.000$ \\
\hline Buying goods and services & $31.3 \%$ & $42.2 \%$ & $\mathrm{Z}=-3.738 ; \mathrm{p}=0.000$ \\
\hline
\end{tabular}




\begin{tabular}{|c|c|c|c|}
\hline Use of the Internet & village & city & test for difference* \\
\hline $\begin{array}{l}\text { Taking part in chat rooms, discussion groups and } \\
\text { forums }\end{array}$ & $5.7 \%$ & $18.0 \%$ & $Z=-6.219 ; p=0.000$ \\
\hline Reading specialized blogs & $5.8 \%$ & $16.3 \%$ & $\mathrm{Z}=-5.478 ; \mathrm{p}=0.000$ \\
\hline Conducting a blog & $0.3 \%$ & $2.9 \%$ & $\mathrm{Z}=-11.520 ; \mathrm{p}=0.000$ \\
\hline
\end{tabular}

$* \mathrm{H}_{0}: \mathrm{p}_{\mathrm{v}}=\mathrm{p}_{\mathrm{c}}$ vs $\mathrm{H}_{\mathrm{a}}: \mathrm{p}_{\mathrm{v}} \neq \mathrm{p}_{\mathrm{c}}$, where $\mathrm{p}_{\mathrm{v}}-$ proportion for village; $\mathrm{p}_{\mathrm{c}}-$ proportion for city

Source: survey results

Turnout in elections is a measure often used to evaluate social capital. Voter turnout in a given area reflects the commitment of people to public affairs and the sense of territorial community, which determines the willingness to cooperate. Participation in the general elections was declared by $80.5 \%$ of rural residents and $81.4 \%$ of the population of the cities, in the local elections by $80 \%$ of rural residents and by $78.9 \%$ of the city population, and in community council elections - by $63.7 \%$ of rural residents and $42.6 \%$ of the city population. Taking into account the local elections, rural areas achieved higher results than urban areas, while in the general elections turnout in rural areas was slightly worse.

Another component of social capital is the sense of identity - a noticeable sense of impact on the surrounding world and the attitude to democracy. The residents of the Lubelskie Region were asked to assess their impact on the affairs of their place of residence. Residents of villages and cities regarded their influence as average, with a slightly better score obtained by villagers (score 3.4) compared to urban residents (score 3.36) (1 - no, 2 - generally no, 3 - I have no opinion, 4 - generally yes, 5 - yes). The attitude to democracy is presented in the following Table 6.

Table 6. Attitude to democracy

\begin{tabular}{|c|c|c|c|}
\hline Characteristics & village & city & test for difference* \\
\hline Democracy is the best form of government & $8.4 \%$ & $10.0 \%$ & $\mathrm{Z}=-0.914 ; \mathrm{p}=0.360$ \\
\hline $\begin{array}{l}\text { Democracy is a rather good form of government, although in some } \\
\text { cases disappointing }\end{array}$ & $48.6 \%$ & $56.6 \%$ & $\mathrm{Z}=-2.654 ; \mathrm{p}=0.007$ \\
\hline $\begin{array}{l}\text { For people like me it does not really matter whether the } \\
\text { government is democratic or non-democratic }\end{array}$ & $5.8 \%$ & $5.6 \%$ & $\mathrm{Z}=0.143 ; \mathrm{p}=0.886$ \\
\hline Democracy is a bad form of government & $15.0 \%$ & $14.1 \%$ & $\mathrm{Z}=0.423 ; \mathrm{p}=0.672$ \\
\hline I have no opinion & $22.2 \%$ & $13.7 \%$ & $\mathrm{Z}=3.690 ; \mathrm{p}=0.000$ \\
\hline
\end{tabular}

$* \mathrm{H}_{0}: \mathrm{p}_{\mathrm{v}}=\mathrm{p}_{\mathrm{c}}$ vs $\mathrm{H}_{\mathrm{a}}: \mathrm{p}_{\mathrm{v}} \neq \mathrm{p}_{\mathrm{c}}$, where $\mathrm{p}_{\mathrm{v}}-$ proportion for village; $\mathrm{p}_{\mathrm{c}}-$ proportion for city

Source: survey results

The last question concerned the assessment of the sense of connection with the settlement, street, people from the neighbourhood and its surroundings, with the locality in which the respondent lived, with the region of residence, with Poland and the European Union. The assessment of the sense of connection is presented in Table 7.

Table 7. Assessment of sense of relationships

\begin{tabular}{|l|c|c|c|}
\hline Characteristics & village & city & test for difference* \\
\hline $\begin{array}{l}\text { Neighborhood, street, people from the neighborhood and } \\
\text { surrounding area }\end{array}$ & 4,07 & 3,72 & $\mathrm{~T}=5,138 ; \mathrm{p}=0,000$ \\
\hline Settlement where he/she lives & 4,10 & 4,08 & $\mathrm{~T}=0,33 ; \mathrm{p}=0,735$ \\
\hline The region in which he/she lives & 4,03 & 4,05 & $\mathrm{~T}=-0,354 ; \mathrm{p}=0,722$ \\
\hline Poland & 4,36 & 4,45 & $\mathrm{~T}=-2,042 ; \mathrm{p}=0,041$ \\
\hline European Union & 3,08 & 3,05 & $\mathrm{~T}=0,429 ; \mathrm{p}=0,667$ \\
\hline
\end{tabular}

$* \mathrm{H}_{0}: \mathrm{m}_{\mathrm{v}}=\mathrm{m}_{\mathrm{c}}$ vs $\mathrm{H}_{\mathrm{a}}: \mathrm{m}_{\mathrm{v}} \neq \mathrm{m}_{\mathrm{c}}$, where $\mathrm{m}_{\mathrm{v}}-$ mean for village; $\mathrm{m}_{\mathrm{c}}-$ mean for city

Scale: 1 entirely unrelated, 2 rather not, unrelated, 3 hard to say, 4 yes, rather tied 5 strongly connected

Source: survey results

\section{CONCLUSIONS AND DISCUSSION}

Poland is not a country with a culture of trust. According to comparative European data, for many years Poles have occupied the lowest positions in the rankings, and so-called generalised trust in Poland is three times lower than the EU average, and six times lower than in the countries with the highest rates (Halamska, 2009). In respect of the low levels of generalised trust, the countryside is no exception. This public trust deficit present in Poland can be explained by the specific and dramatic history of the communist period and the current activities of public authorities. In the case of rural areas, we can add the disturbing impact of collectivisation and repeated attempts to socialise agriculture (Perepeczko, 2003). Of note are also the peasant features of the society, present especially in the countryside. In the peasant culture there is a clear distinction between the inner world, which is well known, and the outside world - strange to the residents of rural areas. Village residents trust above all those who belong to this inner, subjective world. According to research, there is no significant difference in the level of trust between the countryside and the city in most cases, except from the trust in neighbors, the clergy, local government, government and parliament. Residents of villages display a very small degree of generalised trust, also rural residents provide higher assessments in various circles of trust.

According to a survey conducted by the Public Opinion Research Center in 2000-2009, socially active participation was the highest or nearly highest in the countryside, compared to other categories of places of residence, namely the cities 
of various sizes (The activity..., 2010). The study of the years 2000, 2007, 2009 under the Social Diagnosis project indicate that rural residents, when compared with the various groups of urban residents were more engaged in activities for the benefit of the local community. Moreover, studies carried out in 2003 and 2005 show that the country also achieved a good result in this respect, although not the best. The conducted research demonstrated less involvement in community activity in rural areas compared to urban areas of the Lubelskie Region. The difference in the level of the involvement in community activity between the countryside and the city appeared to be significant in cases of most activities.

According to research by Halamska (2009), the membership of villagers in various organisations is quite low and amounts to several percent. According to a survey conducted by the authors, the activity on various types of organisations in villages in the Lubelskie Region is lower than in the cities. Participation in organisations increases with the size of the place of residence of the respondents, their education and income. Networks of non-governmental organisations are less common in the countryside than in the city. The networks are different and have problems specific to the rural environment. Rural organisations are relatively numerous; however the spatial coverage of their activities is comparatively small.

The Internet means strengthening communication and information flow also at the local level. Theoretically, each municipality has its own website. Many parishes and social organisations also have their websites. The Internet is used not only for maintaining contact with persons one already knows, but also to make new contacts, which prevents rural solitude. The Internet is also used to contact various institutions: download forms, search for information on public sector websites and read newspapers. However, according to research, the availability of the Internet in rural areas is significantly much lower than in urban areas, also opportunities offered by the Internet in rural areas are smaller.

Some authors (Bednarek-Szczepańska, 2013) argue that participation in the elections speaks little about horizontal links, ties and social networks, which are at the heart of social capital. However, participation in the elections, both general and local, is the basic mechanism of influence in democratic systems. A large part of the rural population feels obliged to participate in democratic electoral procedures, and many of those who do not participate do not want to admit it. The share of rural residents participating in local elections has always been higher than their participation in the general elections, in line with the common sense of the impact on local matters, which has been confirmed by studies carried out thus far.

After assessing the social capital in rural areas compared to the social capital in urban areas on the basis of the conducted studies, it can be concluded that the differences in the capital in question depend on which component of social capital is taken into account. In a case of the level of trust in people the difference between the city and the village is insignificant. On the other hand, we can observe that the members of rural society are significantly less involved in the local community, and are less active in various organisations. Another thing of note regarding the rural areas in the Lubelskie Region is the lower degree of trust in democracy, greater participation in local elections and a greater sense of local attachment.

\section{REFERENCES}

1. Anderson, C. D., Bell, M. M. 2003. The devil of social capital: a dilemma of American rural sociology. In: Cloke, P. (Ed.), Country Visions, Pearson Education, Essex, pp. 232-244.

2. Bednarek-Szczepańska M. 2013. Spatial differentiation of social capital in Poland - a review. Przegląd Geograficzny, Vol. 85, Iss. 4, pp. 573-597. http://dx.doi.org/10.7163/PrzG.2013.4.4

3. Coleman, J. S. 1990. Foundations of Social Theory, Cambridge, Massachusetts.

4. Final Report: Culture and social capital in the country. Evaluation of cultural support in rural areas by the Programs of the Ministry of Culture, $10^{\text {th }}$ March 2015. http://nck.pl/raporty-analizy/313470-raport-koncowy-kultura-a-kapital-spoleczny-na-wsi-ewaluacjawsparcia-kultury-na-obszarach-wiejskich-poprzez-programy-ministra-kultury-wersja-2-0

5. Friedland, W. 1982. The end of rural society and the future of rural sociology. Rural Sociology, Vol. 47, pp. 589-608.

6. Frieske, K. W. 2004. Utopias inclusions. Successes and failures of social reintegration programs, IPiSS, Warszawa.

7. Fukuyama, F. 1997. Confidence. Social capital and the road to prosperity, PWN, Warszawa.

8. Goudy, W. 1990. Community attachment in a rural region. Rural Sociology, Vol. 55, Iss. 2, pp. $178-198$. http://dx.doi.org/10.1111/j.1549-0831.1990.tb00679.x

9. Halamska, M. 2009. Social Capital of Rural Areas: Attempt at Reconstruction. Przeglad Socjologiczny, Vol. 4(LVII), pp. 69-94.

10. Kasarda, J., Janowitz, M. 1974. Community attachment in mass socjety. American Sociological Review, Vol. 39, No. 3, pp. 328-339. http://dx.doi.org/10.2307/2094293

11. Lannoo, S., Verhaeghe, P. P., Vandeputte, B., Devos, C. 2011. Differences in social capital between urban and rural environments. Journal of Urban Affairs, Vol. 34, pp. 373-394.

12. Park, R. 1915. The city: Suggestions for the investigation of human behavior in the city environment. American Journal of Sociology, Vol. 20, Iss. 4, pp. 577-612. http://dx.doi.org/10.1111/j.1467-9906.2011.00592.x

13. Perepeczko, B. 2003. The post-war social capital determinants of contemporary Polish farmers. Wieś $i$ Rolnictwo, supplement to no 3.

14. Putnam, R. 2000. Bowling Alone - the collapse and Revival of American Community, Touchstone Books, New York.

15. Raczkowska, M. 2009. Social capital on rural areas in Poland. Scientific Papers of Warsaw Agricultural University. Economics and Organization of Food Economy, Vol. 79, pp. 39-47.

16. Social Diagnosis 2000, 2003, 2005, 2007, 2009. University of Finance and Management, the Council for Social Monitoring, Warsaw.

17. The activity of Poles in civic organizations in the years 1998-2010, 2010. Public Opinion Research Center, Warsaw. 
18. Wirth, L. 1938. Urbanism as a way of life. American Journal of Sociology, Vol. 44, Iss. 1, pp. 1-24. http://dx.doi.org/10.1086/217913

19. Zagała, Z. 2008. Social capital: one conceptual category - a lot of controversy, In: Szczepański, M., Bierwiaczonek, K., Nawrocki, T. (ed.) Human and social capital and competitiveness of the regions, Wydawnictwo Uniwersytetu Śląskiego, Katowice, pp. 29-44. 